\title{
NEODYMIUM NEUTRON CROSS SECTION MEASUREMENTS
}

\author{
D. P. Barry ${ }^{1}$, M. J. Trbovich ${ }^{1}$, Y. Danon ${ }^{1}$, R. C. Block ${ }^{1, *}$, R. E. Slovacek ${ }^{1}$, G. Leinweber ${ }^{2}$, \\ J. A. Burke ${ }^{2}$ and N. J. Drindak ${ }^{2}$ \\ ${ }^{1}$ Gaerttner LINAC Laboratory, Rensselaer Polytechnic Institute, Mechanical, Aerospace and Nuclear \\ Engineering Department, Troy, NY 12180-3590, USA \\ ${ }^{2}$ Lockheed Martin Corporation, P.O. Box 1072, Schenectady, NY 12301-1072, USA
}

\begin{abstract}
Neutron capture and transmission measurements were performed by the time-of-flight technique at the Rensselaer Polytechnic Institute LINAC using metallic neodymium samples. The capture measurements were made at the 25-m-long flight station with a 16-segment $\mathrm{NaI}(\mathrm{Tl})$ multiplicity detector, and the transmission measurements were performed at 15 and $25 \mathrm{~m}$ flight stations with a ${ }^{6} \mathrm{Li}$ glass scintillation detector. After the data were collected and reduced, resonance parameters were determined by simultaneously fitting the transmission and capture data with the multilevel R-matrix Bayesian code SAMMY. The resonance parameters for all naturally occurring neodymium isotopes lie within the energy range of 1.0$500 \mathrm{eV}$. The resulting resonance parameters were used to calculate the capture resonance integral with this energy region and were compared to calculations obtained when using the resonance parameters from ENDF-B/VI. The RPI parameters gave a resonance integral value of $32 \pm 0.5 \mathrm{~b}$ that is $\sim 7 \%$ lower than that obtained with the ENDF-B/VI parameters. The current measurements significantly reduce the statistical uncertainties on the resonance parameters when compared with previously published parameters.
\end{abstract}

\section{EXPERIMENTS}

The RPI LINAC facility uses a $60 \mathrm{MeV}$ pulsed electron beam to produce neutrons by means of photonuclear reactions. The electron beam impinges on a water-cooled tantalum target where electrons interact via the Coulomb force and produce bremsstrahlung radiation, which, in turn, generates photoneutrons. The resulting neutrons are moderated and collimated as they travel through a long evacuated flight tube to the sample and detector.

The present RPI neodymium data were obtained from four measurements performed at the RPI LINAC facility. Two of the measurements involved neutron transmission, and two, neutron capture. The details of each experiment are given in Table 1. A channel width entered as $0.25>2.7 \mathrm{eV}$ indicates that for neutron energies $>2.7 \mathrm{eV}$ the channel width was $0.25 \mu \mathrm{s}$.

Two different neutron-production targets were used in the present series of neodymium measurements. The bare-bounce target ${ }^{(1)}$ (BBT) was employed for epithermal transmission and capture measurements. The BBT target geometry is unique in that the tantalum plates are mounted off the neutron beam axis. A 2.54-cm-thick polyethylene moderator is mounted adjacent to the tantalum plates and centred on the neutron beam axis. The moderator effectively slows down the fast neutrons generated in the target through collisions with hydrogen and emits the neutrons at a lower energy. These moderated neutrons then drift down an

${ }^{*}$ Corresponding author: blockr@rpi.edu evacuated flight tube to the detector. The epithermal measurements also incorporate a $0.8-\mathrm{cm}$-thick $\mathrm{B}_{4} \mathrm{C}$ overlap filter placed in-beam to remove low-energy neutrons from a previous pulse.

The enhanced thermal target ${ }^{(2,3)}$ (ETT) was utilised in the thermal transmission and capture measurements. The ETT was designed to produce a high neutron flux for use in thermal measurements. This target is composed of water-cooled tantalum plates, a water moderator, a polyethylene moderator on the neutron beam axis and a graphite reflector.

The time-of-flight (TOF) technique was used to determine the neutron energy for each detected event. The time that it takes for a neutron to travel a known flight path distance to the neutron detector defines the energy of the neutron. The TOF analyser ${ }^{(4)}$ used in these experiments utilises a $32 \mathrm{MHz}$ crystal oscillator coupled to a high-speed scaler with 22-bit resolution. The TOF analyser has a fixed dead time of $0.250 \mu$ s to record each detected event. The overall dead time of the signal processing electronics was $0.6 \mu$ s for transmission experiments and $1.125 \mu$ s for capture experiments. A Hewlett-Packard HP-1000 Model A990 computer was used to record the data and control the sample changer. The sample changer can hold up to eight samples and rotate them in and out of the neutron beam.

Table 2 lists the samples used in each of the RPI neodymium experiments. The samples were composed of natural neodymium metal and sealed inside aluminium sample cans. The thickness of the aluminium on the front and back surface of each sample was $0.51 \mathrm{~mm}$. The additional thickness of aluminium in the sample can was taken into account by including empty sample cans in the measurements. 
D. P. BARRY ET AL.

Table 1. Neodymium experimental details.

\begin{tabular}{lccccc}
\hline Experiment & $\begin{array}{c}\text { Neutron-producing } \\
\text { target }\end{array}$ & $\begin{array}{c}\text { Electron } \\
\text { pulse width } \\
\text { (ns) }\end{array}$ & $\begin{array}{c}\text { Channel } \\
\text { width }(\mu \mathrm{s})\end{array}$ & $\begin{array}{c}\text { Pulse repetition } \\
\text { rate (pulse s }{ }^{-1} \text { ) }\end{array}$ & $\begin{array}{c}\text { Flight } \\
\text { station }(\mathrm{m})\end{array}$ \\
\hline $\begin{array}{l}\text { Epithermal } \\
\text { transmission }\end{array}$ & BBT & $\sim 52$ & $\begin{array}{c}0.25>2.7 \mathrm{eV} \\
0.125>53 \mathrm{eV} \\
0.5>0.5 \mathrm{eV}\end{array}$ & 250 & 25 \\
$\begin{array}{l}\text { Thermal } \\
\text { transmission }\end{array}$ & ETT & $\sim 290$ & $\begin{array}{c}0.25>3.2 \mathrm{eV} \\
0.25>2.7 \mathrm{eV}\end{array}$ & 200 & 15 \\
$\begin{array}{l}\text { Epithermal } \\
\text { capture }\end{array}$ & BBT & $\sim 56$ & $\begin{array}{c}0.125>53 \mathrm{eV} \\
0.5>0.5 \mathrm{eV}\end{array}$ & 25 & 25 \\
$\begin{array}{l}\text { Thermal } \\
\text { capture }\end{array}$ & ETT & $\sim 1000$ & $0.25>3.2 \mathrm{eV}$ & & 25 \\
\hline
\end{tabular}

Table 2. Nd samples used in experiments.

\begin{tabular}{|c|c|c|c|c|}
\hline \multirow{2}{*}{$\begin{array}{l}\text { Nominal } \\
\text { sample } \\
\text { thickness }\end{array}$} & \multicolumn{4}{|c|}{ Experiment } \\
\hline & $\begin{array}{l}\text { Epithermal } \\
\text { transmission } \mathrm{t}\end{array}$ & $\begin{array}{l}\text { Thermal } \\
\text { transmission }\end{array}$ & $\begin{array}{l}\text { Epithermal } \\
\text { capture }\end{array}$ & $\begin{array}{l}\text { Thermal } \\
\text { capture }\end{array}$ \\
\hline 0.0050 .002 & & & $\mathrm{X}$ & $\mathrm{X}$ \\
\hline 0.0130 .005 & & & $\mathrm{X}$ & $\mathrm{X}$ \\
\hline 0.0250 .010 & & & $\mathrm{X}$ & $X$ \\
\hline 0.0510 .020 & $\mathrm{X}$ & & & $X$ \\
\hline 0.0890 .035 & $\mathrm{X}$ & $X$ & & \\
\hline 0.1270 .050 & $\mathrm{X}$ & $\mathrm{X}$ & & \\
\hline 0.2540 .100 & $\mathrm{X}$ & $\mathrm{X}$ & & \\
\hline $\begin{array}{lll}0.508 & 0.200\end{array}$ & $\mathrm{X}$ & $X$ & $\mathrm{X}$ & $X$ \\
\hline 1.0160 .400 & $\mathrm{X}$ & $\mathrm{X}$ & & \\
\hline
\end{tabular}

The length of time for which each sample was placed in the neutron beam was optimised to reduce the counting statistics error in the experiment. The sample characteristics were found previously ${ }^{(5)}$.

The thermal transmission experiments were conducted at the $15-\mathrm{m}$ station which contains a 7.62-cm-diameter (3 in.), 0.3 -cm-thick NE 905 inbeam ${ }^{6} \mathrm{Li}$ loaded scintillator glass $(6.6 \%$ lithium, enriched in ${ }^{6} \mathrm{Li}$ to $95 \%$ ). This thermal transmission detector is used for measurements within the energy range of $0.001-20 \mathrm{eV}$. The epithermal transmission measurements were performed at the $25-\mathrm{m}$ station, which housed a $12.7-\mathrm{cm}$-diameter (5 in.), $1.27-\mathrm{cm}$ thick (0.5 in.) in-beam ${ }^{6} \mathrm{Li}$ loaded Bicron GS-20 scintillator glass $\left(6.6 \%\right.$ lithium, enriched in ${ }^{6} \mathrm{Li}$ to $95 \%$ ). The epithermal transmission detector is used to cover the energy range from 1 to $500 \mathrm{eV}$. Each of the transmission detectors is coupled to a single photomultiplier tube, which is placed in-line with the flight path. The flight path distance for the epithermal transmission detector was $25.597 \mathrm{~m}$ from the BBT, while the flight path for thermal transmission measurements was $14.973 \mathrm{~m}$ from the ETT.

The RPI capture detector ${ }^{(4-6)}$ is a $30.5-\mathrm{cm}$ diameter $\times 30.5$-cm-high $(12$ in. $\times 12$ in. $)$ annular cylinder that contains 16 sections of thallium activated sodium iodide $[\mathrm{NaI}(\mathrm{Tl})]$ scintillator crystals. The cylinder is split, perpendicular to its axis, into two rings, and each ring contains eight equally sized pie-shaped $\mathrm{NaI}(\mathrm{Tl})$ segments. Each $\mathrm{NaI}(\mathrm{Tl})$ segment is optically isolated and hermetically sealed within an aluminium can and mounted on an RCA 8575 photomultiplier. The total volume of $\mathrm{NaI}(\mathrm{Tl})$ within the detector is 20 litres. The incident neutron beam is collimated and directed through an $8.9-\mathrm{cm}-$ diameter (3.5 in.) cylindrical through-hole in the detector, where it impinges upon a sample placed at the centre. A cylindrical boron carbide liner (enriched in $\left.{ }^{10} \mathrm{~B}\right)$ separates the $\mathrm{NaI}(\mathrm{Tl})$ crystals from the sample. The boron liner absorbs neutrons that are scattered from the sample and prevents them from reaching the $\mathrm{NaI}(\mathrm{Tl})$ crystal, thus reducing any scattering background contribution. The detector is surrounded by a 15 -cm-thick (6-in.), $7260 \mathrm{~kg}(16,000 \mathrm{lb})$ lead shield to reduce ambient background. The capture detector is located at a flight path distance of $25.56 \mathrm{~m}$ from the BBT during epithermal capture measurements and $25.41 \mathrm{~m}$ from the ETT during thermal capture measurements. The efficiency of the capture detector is assumed to be the same for all neodymium isotopes.

\section{DISCUSSION AND RESULTS}

Transmission and capture measurements were performed and the resulting data were analysed simultaneously with the R-matrix Bayesian fitting code SAMMY ${ }^{(7)}$ to determine resonance parameters. The final RPI neodymium parameters resulting from the combined SAMMY fits can be found in Ref. (5). Examples of the improvement of the RPI neodymium parameters relative to $\mathrm{ENDF}-\mathrm{B} / \mathrm{VI}^{(8)}$ are presented in Figures 1-4. Figures 1 and 2 show 


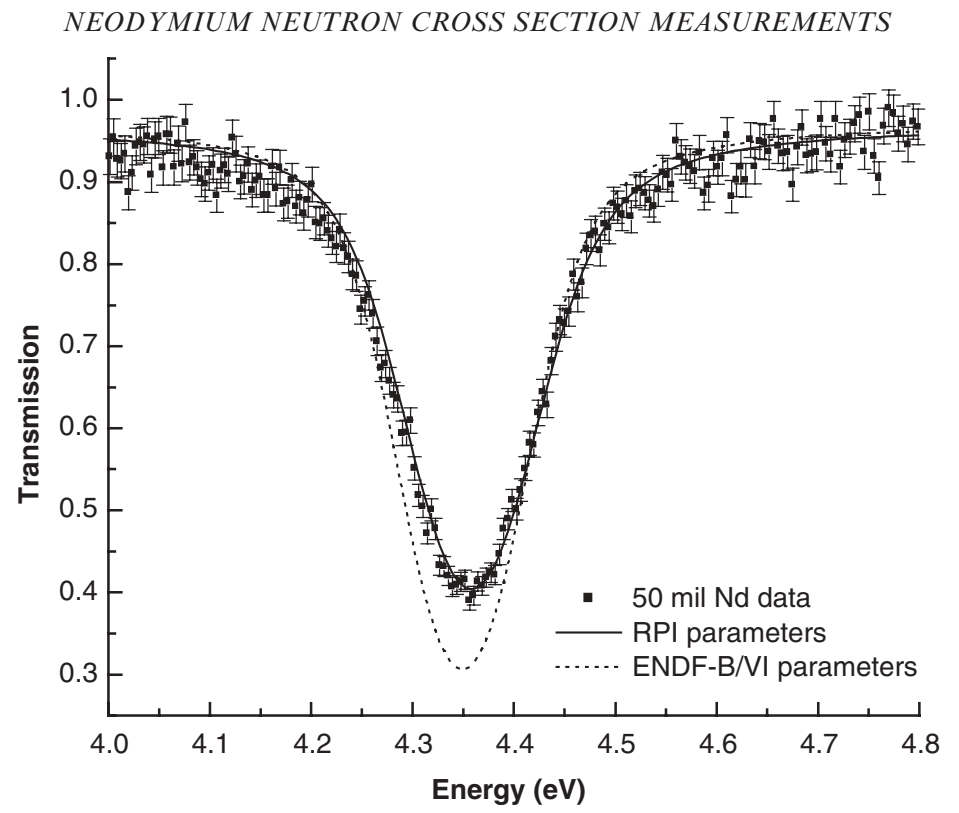

Figure 1. RPI transmission data (solid squares) in a $0.05 \mathrm{in.}(0.127 \mathrm{~cm})$ metallic neodymium sample in the energy region of 4.0-4.8 eV. The resulting SAMMY fits with the final RPI neodymium parameters (solid line) and ENDF-B/VI parameters (dashed line) are shown for comparison.

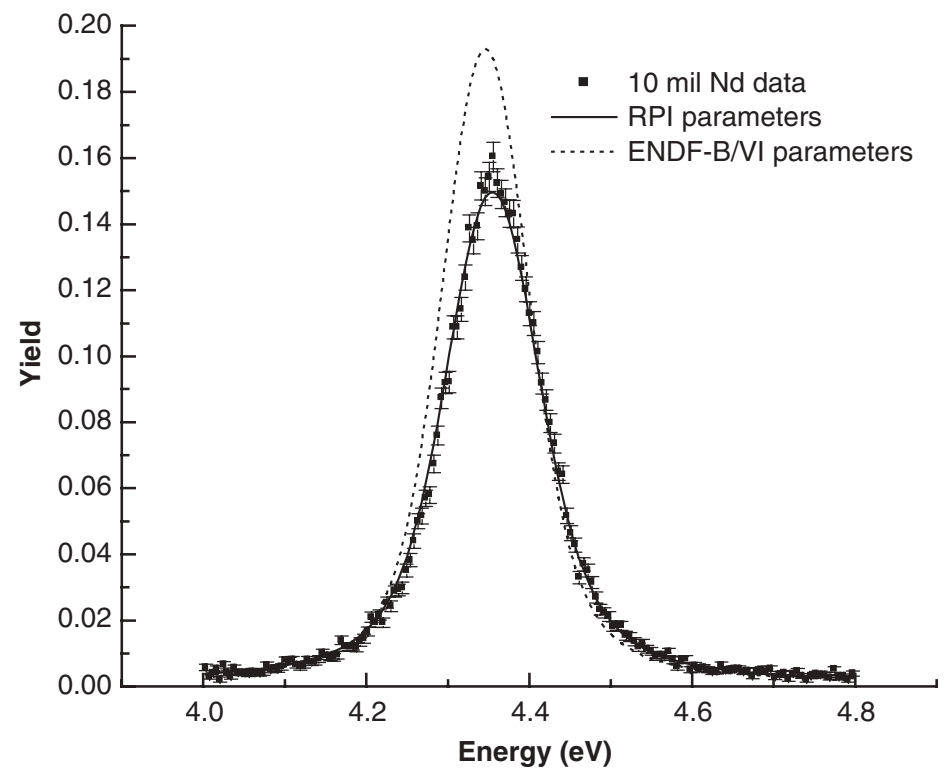

Figure 2. RPI capture data (solid squares) in a 0.01 in. $(0.025 \mathrm{~cm})$ metallic neodymium sample in the energy region of 4.0-4.8 eV. The resulting SAMMY fits with the final RPI neodymium parameters (solid line) and ENDF-B/VI parameters (dashed line) are shown for comparison.

high-quality RPI fits to the neodymium resonance at $4.35 \mathrm{eV}$ for transmission and yield, respectively. It is evident that the RPI neodymium parameters provide a superior fit. Figures 3 and 4 show excellent fits to the resonances in the $330-440 \mathrm{eV}$ energy region for both transmission and capture yield. The RPI parameters fit the data much better than the ENDF-B/VI parameters. 


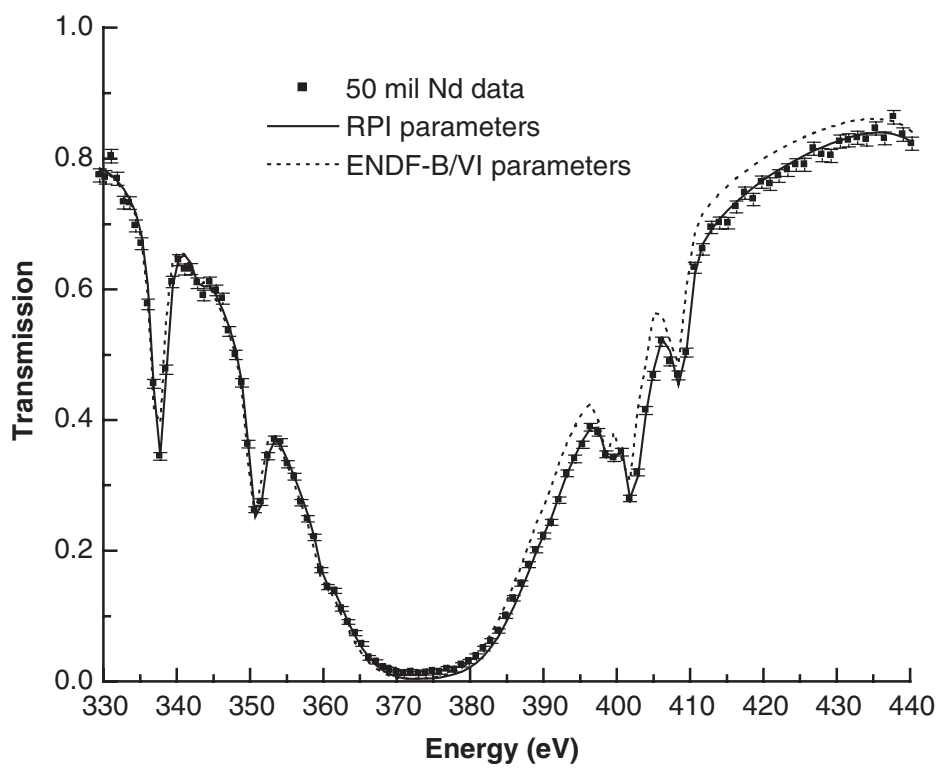

Figure 3. RPI transmission data (solid squares) in a 0.05 in. $(0.127 \mathrm{~cm})$ metallic neodymium sample in the energy region of 330-440 eV. The resulting SAMMY fits with the final RPI neodymium parameters (solid line) and ENDF-B/VI parameters (dashed line) are shown for comparison.

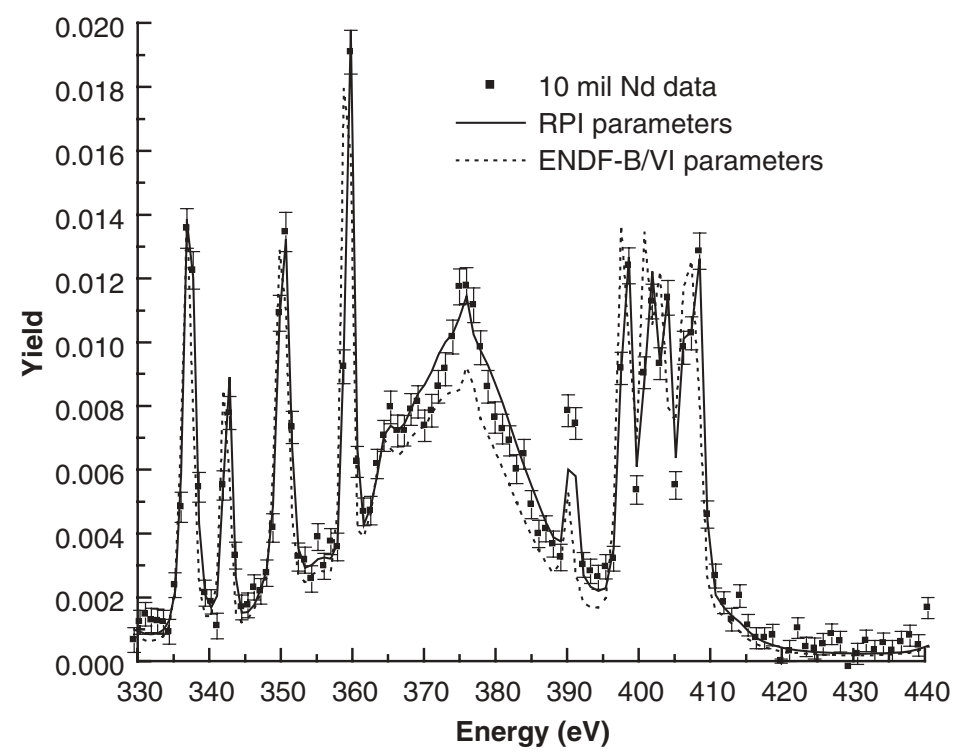

Figure 4. RPI capture data (solid squares) in a 0.01 in. $(0.025 \mathrm{~cm})$ metallic neodymium sample in the energy region of 330-440 eV. The resulting SAMMY fits with the final RPI neodymium parameters (solid line) and ENDF-B/VI parameters (dashed line) are shown for comparison.

The capture resonance integral (RI) was calculated for each neodymium isotope using the codes NJOY $^{(9)}$ and INTER ${ }^{(10)}$. The resonance integrals were calculated for both the final RPI and ENDF-B/VI parameters within the energy region of
$1-500 \mathrm{eV}$. The results are presented in Table 3 for all naturally occurring neodymium isotopes. It should be noted that the ${ }^{142} \mathrm{Nd}$ isotope has no known resonances in this energy region; therefore, the capture resonance integral calculated from the ENDF-B/VI 


\section{NEOD YMIUM NEUTRON CROSS SECTION MEASUREMENTS}

Table 3. Calculated capture resonance integrals for RPI and ENDF-B/VI parameters, respectively.

\begin{tabular}{llcr}
\hline Nd isotope & Abundance $\left(f_{i}\right)$ & \multicolumn{2}{c}{$\begin{array}{c}\text { Capture RIs from } \\
\text { resonances in the } \\
\text { energy range } 1-500 \mathrm{eV}\end{array}$} \\
\cline { 3 - 4 } & & RPI (b) & ENDF (b) \\
& & $(5.834)$ & 5.834 \\
142 & 0.2713 & $89.5 \pm 0.2$ & 89.51 \\
143 & 0.1218 & $4.5 \pm 0.1$ & 3.47 \\
144 & 0.238 & $206.8 \pm 0.5$ & 227.74 \\
145 & 0.083 & $1.08 \pm 0.1$ & 1.21 \\
146 & 0.1719 & $11.0 \pm 0.2$ & 16.97 \\
148 & 0.0576 & $32 \pm 1$ & 34.14 \\
150 & 0.0564 & & $11.69 \pm 0.02$ \\
& $\Sigma \mathrm{RI}_{i} f_{i}$ & & \\
\hline
\end{tabular}

The integrations were performed over the energy region of $1-500 \mathrm{eV}$.

parameters for ${ }^{142} \mathrm{Nd}$ was not changed. The capture resonance integral changes very little for ${ }^{143} \mathrm{Nd}$, while all other capture resonance integrals did change with respect to ENDF-B/VI. The most noticeable change was observed in the ${ }^{145} \mathrm{Nd}$ capture resonance integral, which significantly decreased with the RPI parameters. This change in the capture resonance integral is directly attributed to the changes in the parameters of the $4.36 \mathrm{eV}{ }^{145} \mathrm{Nd}$ resonance. The overall capture resonance integral that includes all neodymium isotopes was calculated to be $32 \pm 0.5 \mathrm{~b}$. This is slightly lower than the ENDF-B/VI capture resonance value of $34.14 \mathrm{~b}$. A method was developed to estimate the errors on each of the resonance integral calculations. This method was propagating the error in the resonance parameters assuming a single-level Breit-Wigner ${ }^{(11)}$ capture cross section.

The energy of the RPI neodymium parameters change very little when compared to the previously published parameters, with the exception of the $4.35 \mathrm{eV}$ resonance. The majority of the RPI values for the neutron width, $\Gamma_{\mathrm{n}}$, appear to be larger than those published previously. The smaller values quoted previously may be due to inaccurate treatment of Doppler broadening or the resolution function shape. The RPI values of $\Gamma_{\gamma}$ are comparable to those published previously ${ }^{(12-14)}$ with the exception of those published by Tellier ${ }^{(12,13)}$. The overall errors on the RPI neodymium parameters are less than those quoted on the previously published parameters. These small errors are attributed to the high-quality RPI measurements that were performed to ensure good counting statistics.

\section{REFERENCES}

1. Overberg, M. E., Moretti, B. E., Slovacek, R. E. and Block, R. C. Photoneutron target development for the RPI linear accelerator. Nucl. Instrum. Methods Phys. Res. A 438, 253 (1999).

2. Danon, Y., Slovacek, R. E. and Block, R. C. The enhanced thermal neutron target at the RPI LINAC. Trans. Am. Nucl. Soc. 68, 473 (1993).

3. Danon, Y., Slovacek, R. E. and Block, R. C. Design and construction of a thermal neutron target for the RPI LINAC. Nucl. Instrum. Methods Phys. Res. A 352, 596 (1995).

4. Slovacek, R. E., Block, R. C., Danon, Y., Werner, C., Youk, G. U., Burke, J. A., Drindak, N. J., Feiner, F., Helm, J. A. and Seemann, K. J. Neutron cross section measurements at the Rensselaer LINAC. In: Proceedings of the Topical Meeting on Advances in Reactor Physics, Knoxville, TN, April 11-15, 1994, Vol. II, p. 193.

5. Barry, D. P. Neodymium neutron transmission and capture measurements and development of a new transmission detector. PhD Thesis, Rensselaer Polytechnic Institute (2003).

6. Block, R. C., Marano, P. J., Drindak, N. J., Feiner, F., Seeman, K. J. and. Slovacek, R. E. A multiplicity detector for accurate low-energy neutron capture measurements. In: Proceedings of the International Conference on Nuclear Data for Science and Technology, Mito, Japan, May 30-June 3, 1988, p. 383.

7. Larson, N. M. Updated users guide for SAMMY: multilevel R-matrix fits to neutron data using Bayes' equations. ORNL/TM-9179/R5. (Lockheed Martin Energy Research Corporations, Oak Ridge National Laboratory, Oak Ridge, TN) (2000).

8. Cross Section Evaluation Working Group. ENDF/ B-VI Summary Documentation. Report BNL-NCS17541 (ENDF-201), Rose, P. R. Ed. National Nuclear Data Center, Brookhaven National Laboratory, Upton, NY (1991).

9. MacFarlane, R. E. and Muir, D. W. The NJOY Nuclear Data Processing System Version 91. LA-12740-M (Los Alamos National Laboratory, Los Alamos, NM) (1994).

10. Dunford, C. L. ENDF Utility Codes Release 6.12. Informal report Brookhaven National Laboratory, Upton, NY (2001).

11. Duderstadt, J.J. and Hamilton, L.J. Nuclear Reactor Analysis (New York: Wiley and Sons) (1976).

12. Tellier, H. Properties of levels induced by resonance neutrons in stable neodymium isotopes. Report CEA-N1459 (France: Commissariat á l'Energie Atomique) (1971).

13. Tellier, H. C. R. Density function for 's' neutron and density parameters of levels of stable isotopes of Nd. Acad. Sc. Paris, Ser. B 272, 695 (1971)

14. Rohr, G., Weigmann, H. and Heske, M. Neutron capture and $\gamma$-ray spectra measurements in resolved resonances for the odd $N d$ isotopes. In: Proceedings of the Conference on Neutron Cross Sections and Technology, Knoxville, TN, p. 743 (March 1971). 